\title{
A digital companion for ecological momentary assessment and prevention of suicide: A case series on the use of the emma app
}

\author{
Morgiève $\mathrm{M}^{1,2,3^{*}}$, Genty $\mathrm{C}^{1}$, Azé $\mathrm{J}^{4}$, Dubois $\mathrm{J}^{1}$, Leboyer $\mathrm{M}^{5,6,7}$, Vaiva $\mathrm{G}^{3,8}$, Berrouiguet $\mathrm{S}^{3,9,10}$, Courtet $\mathrm{Ph}^{1,5}$. \\ ${ }^{1}$ Neuropsychiatrie: recherche épidémiologique et clinique, INSERM, Université Montpellier, Département d'Urgence \& Post Urgence \\ Psychiatrique, CHU Montpellier, Montpellier, France. \\ ${ }^{2}$ ICM - Brain and Spine Institute, Hôpital de la Pitié-Salpêtrière, 47-83, boulevard de I’hôpital, 75013 Paris, France. \\ ${ }^{3}$ GEPS - Groupement d'Étude et de Prévention du Suicide, France. \\ ${ }^{4}$ LIRMM, UMR 5506, Montpellier University/CNRS, 860 rue de St Priest, 34095 Montpellier, France. \\ ${ }^{5}$ Fondation Fondamental, hôpital Albert-Chenevier, 40, rue de Mesly, 94000 Créteil, France \\ ${ }^{6}$ Université Paris Est Créteil, Faculté de Médicine, Institut National de la Santé et de la Recherche Médicale, Créteil, France. \\ ${ }^{7}$ Assistance Publique Hôpitaux de Paris, Pôle de Psychiatrie et Addictologie, Hôpitaux Universitaires Henri Mondor, Créteil, France. \\ ${ }^{8}$ CHU Lille, Hôpital Fontan, Department of Psychiatry, 59000, Lille, France. Université de Lille, Centre National de Ressources \& Résilience \\ pour les psychotraumatisme, Lille - Paris, France. \\ Université de Lille, CNRS UMR-9193, SCALab - Sciences Cognitives et Sciences Affectives, France. \\ ${ }^{9}$ EA 7479 SPURBO, Université de Bretagne Occidentale, Brest, France. \\ ${ }_{10}$ IMT Atlantique, Lab-STICC, 29238 Brest, France.
}

\section{Abstract}

Background: Many suicide risk factors have been identified, but traditional clinical methods do not allow the accurate prediction of suicide behaviors. To face this challenge, we developed emma, an app for Ecological Momentary Assessment/Intervention (EMA/EMI) and prediction of suicide risk in high risk patients.

Objective: We wanted to test the feasibility of implementing this mHealth-based suicide risk assessment and prevention tool and its impact in subjects at high risk of suicide in real world conditions.

Methods: The EMMA Study is an ongoing longitudinal interventional multicenter trial in which patients at high-risk for suicide $(n=100)$ use emma for 6 months. During this period, they complete four EMA types (daily, weekly, monthly, spontaneous) and may use EMI modules. Participants undergo clinical assessment at month 0, 1, 3 and 6 after inclusion.

Results: Among the 43 patients already recruited in the EMMA Study, 14 participants had completed the follow-up. Their data were analyzed to evaluate emma implementation and impact on suicide risk management. EMA completion rates were extremely heterogeneous among the 14 participants with a sharp decrease over time. The completion rates of the weekly EMA (25\% to $87.5 \%$ ) were higher than for the daily EMA ( $0 \%$ to $53.3 \%)$. Most patients $(n=10 / 14)$ answered the EMA questionnaires spontaneously. Similarly, the Safety Plan Modules use was very heterogeneous ( 2 to 75 times). Specifically, 11 patients used the Call Module (1 to 29 times), designed by our team to help them to get in touch with healthcare professionals and/or relatives during a crisis. All patients used the Breathing Space Module and 8 the Emotion Regulation Module (1 to 46 times). The diversity of patient profiles and use of the EMA and EMI modules proposed by emma was highlighted by three case reports.

Conclusions: These preliminary results suggest that it is possible and acceptable to collect longitudinal fine-grained contextualized data (EMA) and to offer personalized intervention (EMI) in real time to people at high risk of suicide. Patients have different clinical and digital profiles and needs that require a highly scalable, interactive and customizable app. To become a complementary tool for suicide prevention, emma should be integrated in the existing emergency procedures.

Trial Registration: ClinicalTrials.gov NCT03410381, https://clinicaltrials.gov/ct2/show/NCT03410381.

Key words: Suicide, Ecological Momentary Assessment, Prediction, Prevention, Mobile health (mHealth), Case reports, Ecological Momentary Intervention. 


\section{BACKGROUND \\ Context}

According to the World Health Organization (WHO) suicide is the cause of one million deaths per year (nearly $2 \%$ of all deaths worldwide), and should increase to 1.5 million by 2020 [1,2]. The WHO recognizes suicide prevention as a public health priority [1]. History of suicide attempts is the most important risk factor of suicide death in the general population, and is present in about $40 \%$ of suicides $[3,4]$. Patients who come to the emergency department (ED) following a suicide attempt present an extremely high risk of suicide in the short term [5-7].

People at risk of suicide often do not seek help and do not remain connected to the health service after an attempt [8]. Access to mental healthcare is inversely correlated with the suicide rate [9]. It is reported that less than half of patients at risk of suicide are in contact with the health system, including mental health services [10], partly because they think they will "get on by themselves" [11]. Access to care is hindered by attitudinal (e.g., no hope or trust in treatments, stigma, shame, previous contact with psychiatry [12], refusal or avoidance of help, "help-negation") and structural barriers (e.g., financial, geographical, and issues with healthcare access, etc.) [13] 14]. It can be hypothesized that factors and traits of vulnerability to suicidal behavior (impulsivity, hostility, decision-making anomalies correlated with interpersonal problems, emotional dysregulation, hypersensitivity to social rejection, reduced perception of social support, despair) facilitate and amplify these difficulties of access and adherence to care.

\section{Ecological Momentary Assessment}

Often, suicidal risk is exacerbated when patients are in their natural environment, far from the healthcare system, in their daily life [15]. Therefore, real-time emotional, behavioral and psychological assessments could improve the identification of high-risk individuals who require rapid interventions. Ecological Momentary Assessment (EMA), also commonly defined as experience sampling method, allows collecting longitudinal fine-grained data as they occur in the real world. It gives an accurate picture of the patient's symptoms [16], and reduces the impact of self-report response bias, thus leading to a better appreciation of the temporal dynamics of suicide risk [17]. Davidson et al. regretted that this method has been fairly neglected in suicidology [18]. Indeed, only ten studies have used real-time monitoring to assess suicidal thoughts [19], although compliance with daily life repeated assessments is high across populations with different suicide and suicidal ideation risks [20]. Moreover, no iatrogenic effect related to repeated assessments of suicidal ideation was found [20-22], and several studies even suggested potential benefits. According to Davidson et al [18], patients may feel less hopeless by following their suicidal ideation changes over time. Other studies suggested that EMA could decrease suicidal ideation [21,23].

Typically, suicidal ideation is episodic, with a quick onset [24] and short duration (shorter than an hour) [25]. Suicidal thoughts vary dramatically among individuals [19], and fluctuating or persistent suicidal thoughts are associated with the risk of different suicidal behavior types [25]. Currently, suicidal thoughts are intermittently assessed at intervals that can go from weeks to years [26], and suicidal thoughts "in the wild" cannot be observed and monitored [24] because they can vary within few hours $[24,27,28]$. Furthermore, suicide attempts can occur in response to a rapid increase in suicidal thoughts within a very short time (one day) $[15,24,29]$. These observations highlight the importance of not relying on intermittent assessments of suicidal ideation for clinical decisionmaking (such as hospital discharge) $[24,30]$. Mobile health (mHealth) interventions are a promising way to assess these fluctuations in real time.

\section{Ecological Momentary Intervention for suicide prevention}

The safety plan intervention [42] is one of the recommended strategies in suicide prevention guidelines [43], and is considered as a therapeutic intervention on its own [44]. At the ED, patients with suicidal ideation and clinicians identify the warning signs and write together a personalized crisis plan that can be used at times of crisis [44]. The Zero Suicide Model [45] recommends this evidence- 
based best practice brief intervention that allows reducing lethal means, promoting brief problem solving and coping skills, increasing social support, and identifying emergency contacts to use during a suicide crisis.

Digital tools could increase the effectiveness of these prevention strategies. Indeed, apps are affordable and ubiquitous, and can be used in any situation, particularly during a crisis [46]. The WHO recommends them for people at risk of suicide [1] because they offer new opportunities to overcome some of the help-seeking barriers [14,47-49], and enhance safety planning [43] in response to dynamic suicidal processes in real-time [24].

\section{Hypothesis and aims}

We hypothesized that it is possible to assess and prevent suicidal behaviors in real time in high-risk patients using digital tools. To test this hypothesis, we developed emma, an app to monitor the psychological, emotional and social fluctuations of patients in their daily life. In addition to EMA, the app includes also interactive and customized EMI modules for suicide prevention. This app is currently tested in an on-going trial (EMMA study). Here, we performed a descriptive analysis of selected patients at high risk of suicide to obtain insights into the feasibility of implementing a $\mathrm{mHealth}$-based suicide risk assessment and prevention procedure in real life conditions.

\section{Objectives}

The main objective of the present study was to assess the feasibility of implementing a mHealthbased tool to assess and prevent suicidal behaviors in real life conditions in a sample of individuals at high risk of suicide.

The secondary objectives were:

- To describe typical user profiles of the emma app;

- To describe relevant qualitative elements from the interviews of participants who completed the 6-month study.

\section{METHODS/DESIGN}

\section{Study design}

The EMMA project includes two successive clinical studies:

- Step 1 (EMMA Study): Building a suicide predictive algorithm based on the EMA data supplied by high-risk patients $(n=100)$ through the emma app

- Step 2: Validation of the algorithm effectiveness in a larger sample $(n=500)$.

The EMMA Study is an on-going prospective longitudinal interventional multicenter trial (involving four French university hospitals in Montpellier, Lille, Brest, and Créteil) completed by a qualitative study. The protocol was registered in the Clinical Trials Registry (ClinicalTrials.gov; number: NCT03410381, 18/01/2018), was authorized by the French Health Ministry (ANSM, 30/11/2017), and approved by the Est IV Ethical Committee for the Protection of Patients (10/10/2017).

\section{Participants}

The EMMA Study plans to recruit 100 patients from EDs and mental health departments. Patients are included after a suicide attempt ( $<8$ days) and/or if they had suicide ideation (IDSC-30 scale score $\geq 2$ ). The other inclusion criteria are: aged 18 years or older, signature of the informed consent, and possession of a smartphone (iOS or Android). Exclusion criteria are: refusing to participate, under guardianship, protected by law, deprived of liberty, not affiliated to a social security system, in a period of exclusion from other trials, and unable to understand the study.

\section{Procedure}

At inclusion, a psychiatrist performs the first interview to ensure that the patient meets the eligibility criteria and to obtain the informed written consent. Four clinical assessments are conducted, at inclusion and at month 1, 3 and 6 . Clinical data are collected by: 
1) Hetero-evaluation: presence of psychopathology (Mini-International Neuropsychiatric Interview \& Structured Clinical Interview, MINI [61]), depression intensity (Inventory of Depressive Symptomatology, IDS [62]), and suicidal spectrum (Columbia-Suicide Severity Rating Scale, C-SSRS [63]; Risk-Rescue Rating Scale, RRRS [64]; Risk Rescue and Suicidal Ideation Scale, SIS [65]).

2) Self-assessment questionnaires: depression (Quick Inventory of Depressive Symptomatology, QIDS [62]); childhood abuse (Childhood Trauma Questionnaire-Short Form, CTQ-SF [66]); loneliness [67], social isolation [68], attachment [69], and hopelessness (Beck Hopelessness Scale, BHS, [70]); impulsivity [71] and emotion regulation (Difficulties in Emotion Regulation Scale, DERS [72]); Interpersonal Needs Questionnaire [73]; reasons for living (RFL [74]); Meaning in Life [75], and quality of life (SF-36 [76]).

Satisfaction concerning the app is evaluated in three distinct ways: i) questionnaire about the usefulness and satisfaction of the app administered every month via emma, ii) standardized selfadministered questionnaire (Mobile App Rating Scale, MARS [81]) at the end of the study, and iii) qualitative semi-structured interview about the participant's subjective experience.

At inclusion, a member of the research team helps patients to install, configure and personalize the app. Patients are asked to use emma for 6 months. Data collected during the assessments made by clinicians as well as data and metadata resulting from emma use are encrypted and stored in a secure server. All these data will be used to develop the algorithm to predict suicidal risk (Figure 1). Considering the crucial issue of health data privacy and security, multi-level technical and organizational safeguards were put in place. The app is secured by a password, as requested by the co-designer patients, and data are anonymized, encrypted, and stored in a secure server to prevent unauthorized data disclosure or breach, as recommended by European General Data Protection Regulation (GDPR).

Figure 1. Visual description of the study

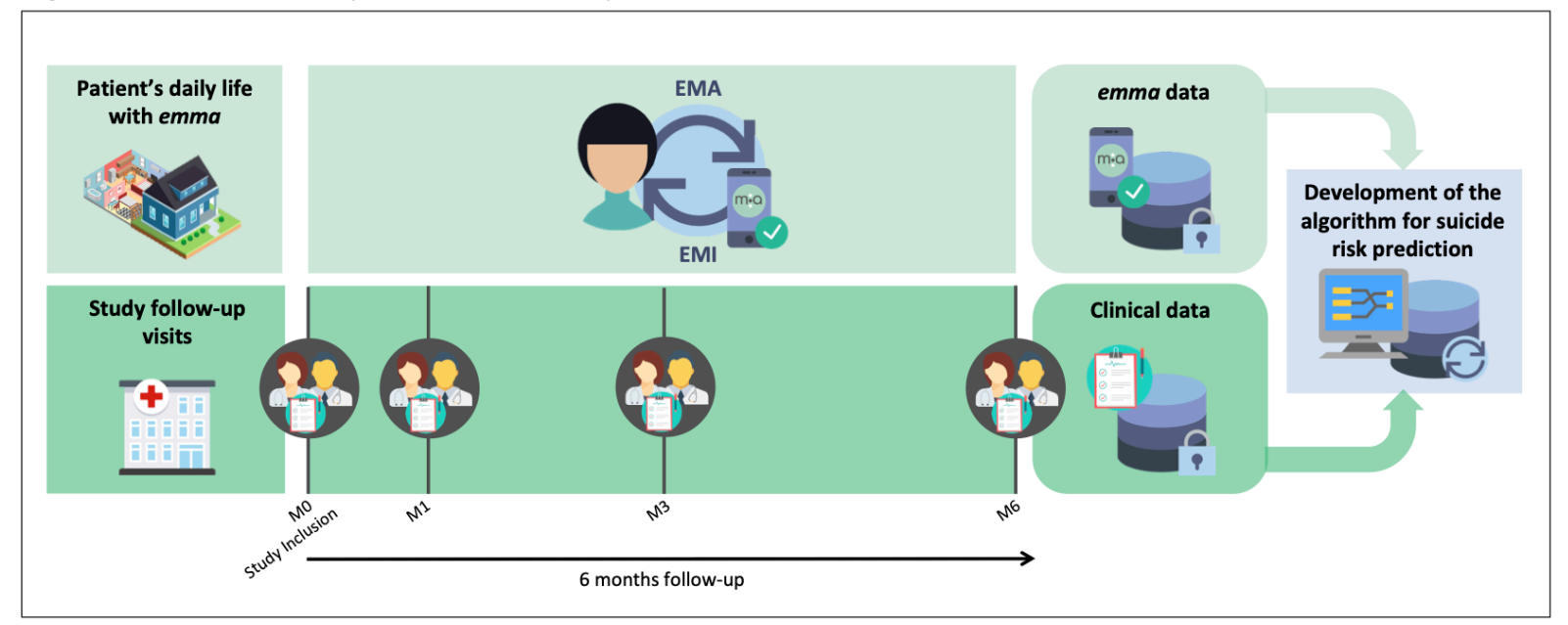

\section{Outcome Measures}

The principal outcome measure of this study was the quantitative description of the app use: completion of the EMA questionnaires and use of EMI modules.

The secondary outcome measures were:

- Quantitative description and app use timeline in few selected patients to illustrate different users' profiles;

- Qualitative analysis of selected interviews of participants who completed the 6-month follow-up.

\section{Emma design}

Emma is a smartphone app we developed for the assessment, prevention, and ultimately prediction of suicidal behaviors. It was designed by integrating evidence-based suicide prevention strategies 
and recommendations for the development of apps in the field of mental health [50,51]. Emma design was based on theoretical literature data and on the practical data obtained by our research team by testing the available suicide-related apps. Emma was developed for Android and iOS for wide usage.

Emma was conceived using a participatory design approach that included patients with suicidal thoughts/behaviors as equal partners of our professional multidisciplinary team (researchers, psychiatrists, psychologists, sociologists, computer scientists, engineers and data scientists) from start to finish [52,53]. This ensured that emma meets scientific and technical standards [54] as well as the patients' needs [55-57]. To this aim an user-involving methodology based on focus groups [58] was implemented. Early in the development process, the involved patients stressed the importance of having a secured password to open the app, and contributed to the choice of the name "emma" that they wanted to be not stigmatizing, and without any mention of psychiatry or suicide. A group of co-designer patients $(n=5)$ and clinical staff $(n=5)$ tested extensively the app for 3 months, and their feedback was taken into account in an iterative way by the developers at the Laboratory of Informatics, Robotics and Microelectronics of Montpellier (LIRMM) to improve the app. This allowed ensuring that the notifications asking to fill in the EMA questionnaires were not leading to interruption/disruption in the users' daily activities in order to maximize emma acceptability, use [56], and validity [59].

\section{Emma contents}

Emma allows patients to define and personalize their own safety plan based on the steps defined by Stanley and Brown [42], and was designed to be used as a self-help tool for suicidal crisis management. Patients are invited to identify: A) their warning signs (e.g., negative feelings and problematic behaviors); B) their individualized coping strategies (e.g., "Breathing Space": audio awareness guide made specifically for emma by a psychiatrist expert in suicidal behavior); $C$ ) their distraction activities (e.g., favorite places and activities, libraries of music and pictures that are known to help with emotional regulation [46] and to connect with the patient's reasons for living); D) their social support (e.g., collating the contact details of the patient's social network, mental health professionals, and other crisis resources). This module promotes connectedness, a major protective factor in suicide prevention [47].

Emma does not include advices to make the environment safe in order to avoid any risk related to the cognitive availability of access to lethal means that could potentially encourage risky behaviors [60].

To improve treatment access and adherence, drug management and therapy session reminders are proposed by the app, and the patient may fill in a diary.

As recommended, an app section provides information (text and video) on how emma was designed, how to use it, how to contact the team, and on the legal notice that specifies the secure data storage. Examples of emma screens are shown in Figure 2. 
Figure 2. Emma screenshots

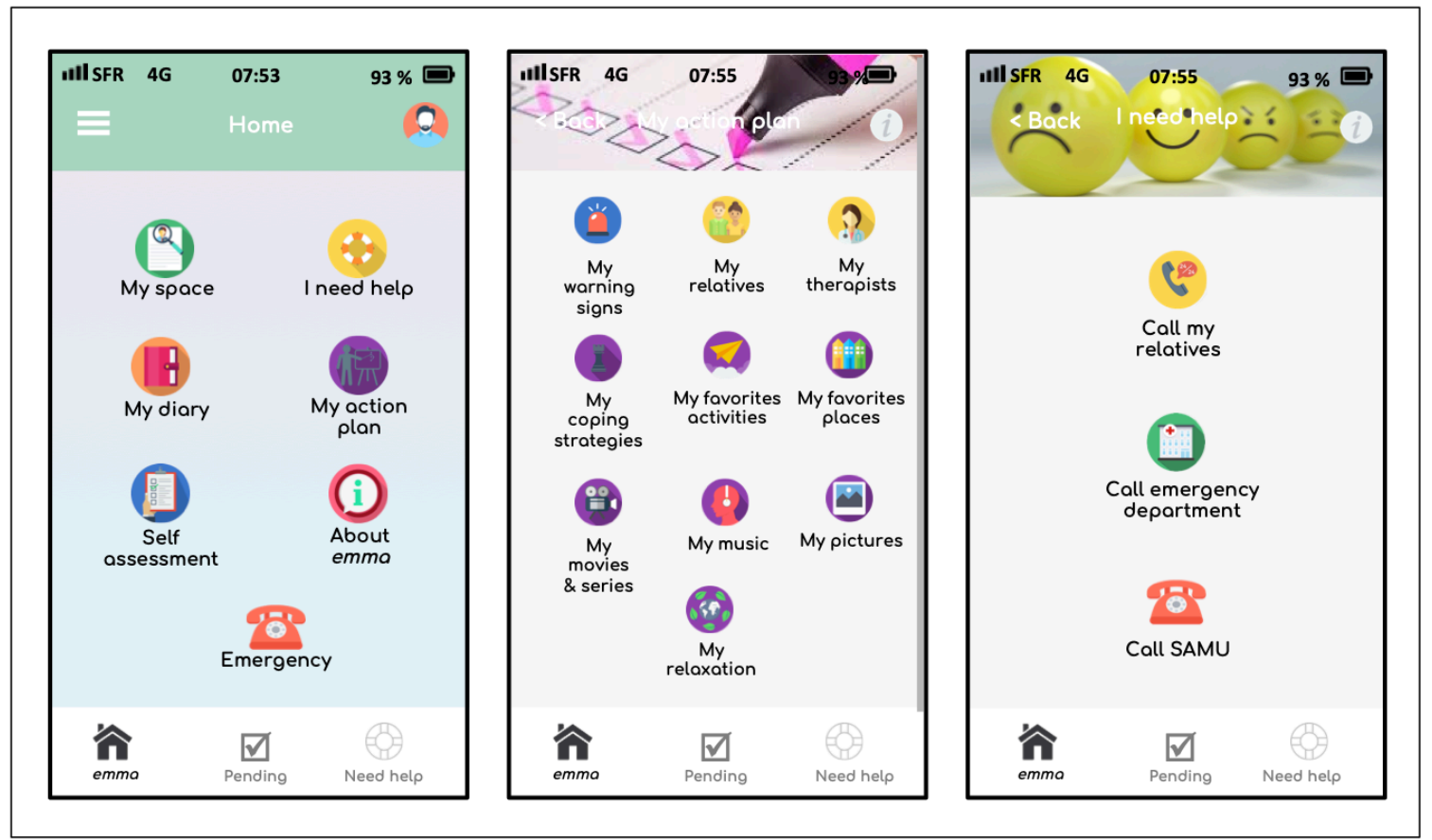

Emma proposes four brief EMA types: three scheduled evaluations at pre-determined frequencies (daily, weekly, and monthly), and one spontaneous assessment (Figure 3). We defined alarm thresholds on the basis of the patient's answer to critical questions that lead to the automatic suggestion of adapted EMI modules (Figure 4). For each EMI module, the app presents a list of suggestions (their content and order can be changed). Modules are designed to be adaptable to the user's state, needs, and strategies.

Figure 3. EMA types proposed by emma

Daily (5 times per day, for 3 days, each month):
Suicidal ideation/behaviors, emotions, thoughts, behaviors and where/
when they occurred.
Weekly:
Summary of the week focused on suicidal ideation/behaviors,
relationships (family, friends \& colleagues) and quality of life.
Monthly:
Perception, experience \& satisfaction about the emma app.
Spontaneous: when patients feel the need.
As in the daily EMA.


Figure 4. Algorithm for automatic EMI triggering according to the EMA answer thresholds

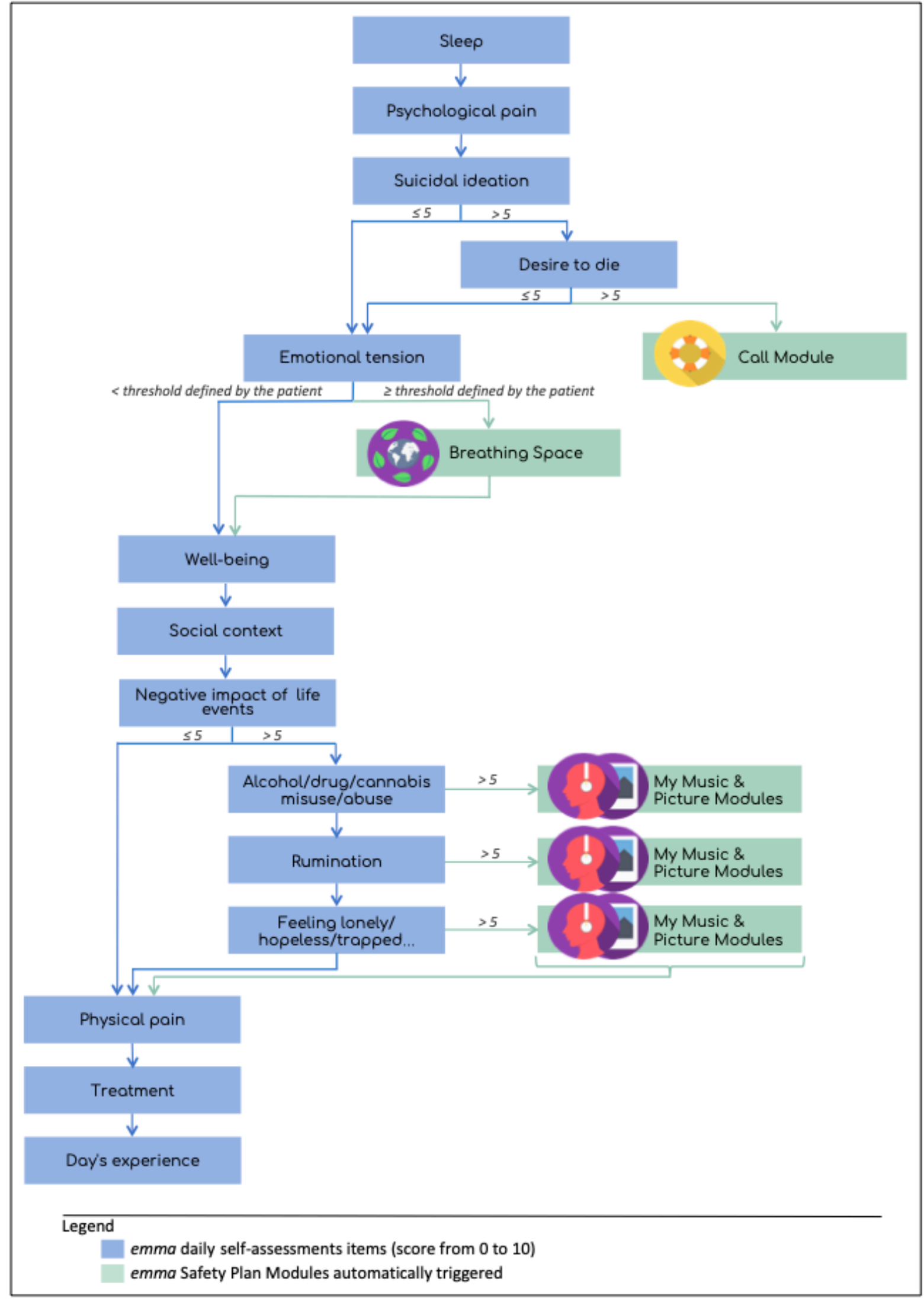




\section{RESULTS}

\section{Baseline assessment}

From May 2018 to March 2019, 43 patients at risk for suicide (recent attempters or current ideators) were selected for the EMMA study at EDs and post-emergency departments, and $38(88 \%)$ agreed to participate. Five patients refused because they considered the study duration ( 6 months) too long. The present analysis included the 14 patients who have already completed the study (Figure 5). Their sociodemographic and clinical data are reported in Table 1 and 2, respectively. These first emma users were mostly women $(n=12 / 14)$, with an mean age of 34 years (18-57 years). All participants presented at least one mental disorder, according to the DSM- 5 criteria, and most of them more than one (up to five comorbid disorders); $43 \%$ were recent suicide attempters ( $\leq 8$ days), and they all had severe suicidal ideation (average C-SSRS score: $22 / 25$, range: 15 to 25 ).

During the study, four patients were admitted to the ED (suicide ideation and/or suicide attempt) 1 to 3 times, and one patient made a suicide attempt without ED admission (Supplemental Table).

Two patients left before the first follow-up visit (one was excluded because she was restrained, and the other one withdrew from the study).

Figure 5. Flowchart of patients' selection

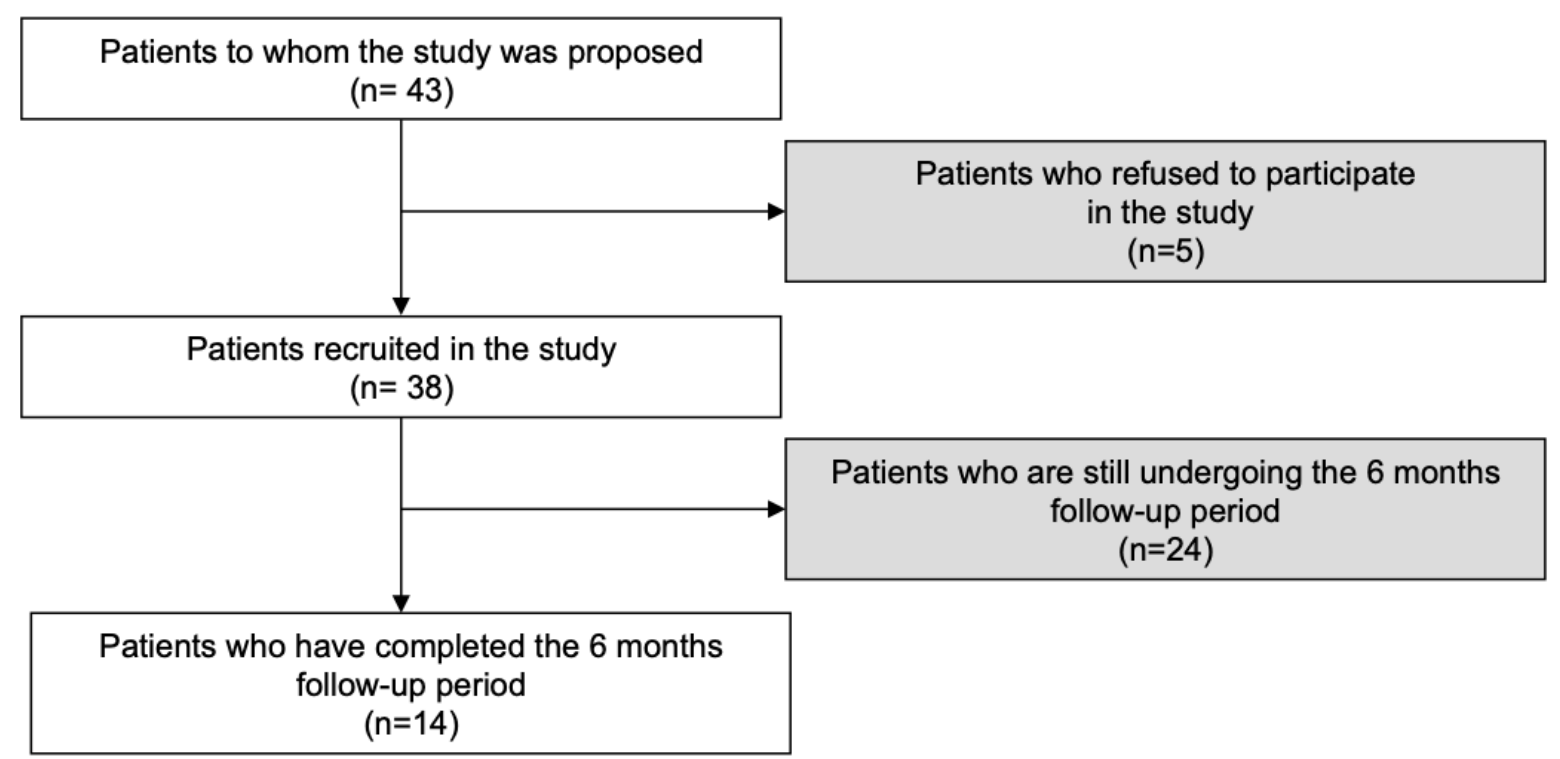

Table 1. Sociodemographic data

\begin{tabular}{lllllll}
\hline Patient & Sex & Age & Marital status & $\begin{array}{l}\text { Number } \\
\text { children }\end{array}$ & of & Cohabitation \\
\hline 1 & Female & 24 & Single & 0 & Lives alone & Professional situation \\
\hline 2 & Female & 18 & Single & 0 & With family & Working (stable) \\
\hline 3 & Female & 27 & In a relationship & 0 & Lives alone & Volunteer \\
\hline 4 & Female & 33 & In a relationship & 2 & With family & Working (stable) \\
\hline 5 & Female & 40 & In a relationship & 2 & With family & Working (precarious) \\
\hline 6 & Female & 46 & Separated & 3 & Non-family cohabitation & Without activity, at home \\
\hline 7 & Female & 30 & Single & 0 & Lives alone & Disability \\
\hline 8 & Male & 48 & In a relationship & 2 & With family & Sick leave \\
\hline 9 & Female & 57 & Separated & 4 & With family & Disability \\
\hline 10 & Female & 48 & In a relationship & 2 & With family & Sick leave \\
\hline 11 & Female & 21 & In a relationship & 0 & Non-family cohabitation & Student/Training \\
\hline 12 & Female & 23 & Single & 0 & Lives alone & Student/Training \\
\hline 13 & Male & 18 & Single & 0 & With family & Student/Training \\
\hline
\end{tabular}




\begin{tabular}{|c|c|c|c|c|c|c|}
\hline 14 & Female & 48 & Separated & 1 & Lives alone & Working (stable) \\
\hline
\end{tabular}

Table 2. Clinical data

\begin{tabular}{|c|c|c|c|c|c|c|c|c|}
\hline Patient & $\begin{array}{ll}\text { Current } & \text { DSM-5 } \\
\text { diagnoses }\end{array}$ & $\begin{array}{l}\text { Borderline } \\
\text { personality }\end{array}$ & $\begin{array}{l}\text { Suicidal } \\
\text { risk in the } \\
\text { near } \\
\text { future } \\
\text { according } \\
\text { to the } \\
\text { DSM-5 }\end{array}$ & $\begin{array}{l}\text { Suicidal } \\
\text { ideation } \\
\text { intensity* }\end{array}$ & $\begin{array}{l}\text { Number } \\
\text { of suicide } \\
\text { attempts }\end{array}$ & $\begin{array}{l}\text { Characteristics } \\
\text { of } \\
\text { severe/violent } \\
\text { suicide } \\
\text { attempt** }\end{array}$ & $\begin{array}{l}\text { Family } \\
\text { history of } \\
\text { suicide } \\
\text { attempt }\end{array}$ & $\begin{array}{l}\text { Family } \\
\text { history of } \\
\text { suicide }\end{array}$ \\
\hline 1 & $\begin{array}{l}\text { Major depressive } \\
\text { disorder }\end{array}$ & & Yes & 22 & 2 & & No & No \\
\hline 2 & $\begin{array}{l}\text { Major depressive } \\
\text { disorder } \\
\text { Agoraphobia } \\
\text { Social phobia } \\
\text { Anorexia }\end{array}$ & Yes & Yes & 25 & 2 & & No & No \\
\hline 3 & $\begin{array}{l}\text { Major depressive } \\
\text { disorder } \\
\text { Agoraphobia } \\
\text { Social phobia } \\
\text { Bulimia } \\
\end{array}$ & Yes & No & 25 & 30 & $\begin{array}{l}\text { Violent }(n=2) \\
\text { Severe }(n=1)\end{array}$ & Yes & No \\
\hline 4 & $\begin{array}{l}\text { Major depressive } \\
\text { disorder }\end{array}$ & & Yes & 25 & 2 & & Yes & No \\
\hline 5 & $\begin{array}{l}\text { Major depressive } \\
\text { disorder } \\
\text { Severe alcohol } \\
\text { and substance- } \\
\text { related disorder } \\
\text { Bulimia } \\
\text { Bipolar disorder II }\end{array}$ & & No & 23 & 1 & & Yes & Yes \\
\hline 6 & $\begin{array}{l}\text { Major depressive } \\
\text { disorder } \\
\text { Severe alcohol- } \\
\text { related disorder }\end{array}$ & & Yes & 15 & 2 & & No & No \\
\hline 7 & $\begin{array}{l}\text { Major depressive } \\
\text { disorder } \\
\text { Generalized } \\
\text { anxiety disorder } \\
\text { Bipolar disorder I }\end{array}$ & & Yes & 25 & 55 & Violent $(n=15)$ & No & No \\
\hline 8 & $\begin{array}{l}\text { Major depressive } \\
\text { disorder } \\
\text { Social phobia } \\
\text { Severe alcohol- } \\
\text { related disorder } \\
\text { Generalized } \\
\text { anxiety disorder } \\
\text { Bipolar disorder I }\end{array}$ & & No & 25 & 1 & & Yes & No \\
\hline 9 & $\begin{array}{l}\text { Major depressive } \\
\text { disorder } \\
\text { Agoraphobia } \\
\text { Post traumatic } \\
\text { disorder } \\
\text { Bipolar disorder II }\end{array}$ & & Yes & 25 & 8 & Severe $(n=1)$ & No & No \\
\hline 10 & $\begin{array}{l}\text { Major depressive } \\
\text { disorder }\end{array}$ & & Yes & 24 & 1 & & Unknown & Yes \\
\hline 11 & $\begin{array}{l}\text { Generalized } \\
\text { anxiety disorder }\end{array}$ & & Yes & 16 & 1 & & Yes & No \\
\hline 12 & $\begin{array}{l}\text { Major depressive } \\
\text { disorder } \\
\text { Agoraphobia } \\
\text { Social phobia } \\
\text { Bulimia } \\
\end{array}$ & & Yes & 19 & 0 & & Yes & Yes \\
\hline 13 & $\begin{array}{l}\text { Major depressive } \\
\text { disorder } \\
\text { Social phobia } \\
\text { Generalized } \\
\text { anxiety disorder }\end{array}$ & Yes & Yes & 20 & 3 & & No & No \\
\hline 14 & Major depressive & & No & 18 & 1 & & No & No \\
\hline
\end{tabular}


* sums of items 7 to 11 of the C-SSRS, scores from 0 to 25 .

** Violent suicide attempt was defined by the method violence: weapons, hanging, jumping from a height, traffic, drowning, or immolation. Severe suicide attempt: suicide attempt requiring hospitalization in intensive care unit.

\section{Principal outcome}

The completion rates were higher for the weekly than daily EMAs ( $25 \%$ to $87.5 \%$, and $0 \%$ to $53.3 \%$, respectively). Moreover, they were extremely heterogeneous among participants with a sharp decrease over time. Most patients $(n=10 / 14)$ filled in the questionnaires spontaneously at times of crisis (from 1 to 39 times).

Similarly, use of the Safety Plan Modules (EMI) varied among patients ( 2 to 75 times). Most patients ( $n=11$ ) used the Call Module (1 to 29 times) to get in touch with the healthcare system and/or family and friends during a crisis. Most patients $(n=10)$ called the SAMU (French national emergency medical assistance service available 24/7; 1 to 15 times), 8 their relatives ( 1 to 7 times), and 7 their ED ( 1 to 7 times). About half of the patients $(n=8)$ used one of the Emotion Regulation Modules ( 1 to 46 times). Specifically, eight listened to the Breathing Space Module (1 to 5 times), while only four looked at Pictures (1 to 41 times), and two listened to Music ( 2 and 7 times).

\section{User profiles}

Three users are described in detail to better illustrate the different emma uses. These patients were chosen to reflect the diversity of patients' clinical profiles and of emma use (i.e., completion rate of the scheduled EMAs and use of the Safety Plan Modules).

\section{Patient 7}

Patient 7 is a 30-year-old single woman living alone, without children, unemployed and benefiting from the disability living allowance for adults (Table 1). At inclusion, she had major depressive disorder, generalized anxiety disorder, and bipolar disorder I, according to the DSM-5. She had 55 previous suicide attempts of which 15 violent, and a maximal suicidal ideation intensity at inclusion (C-SSRS score of 25/25) (Table 2). Therefore, she was at very high risk, and the period following hospitalization is known to be particularly at risk of recurrence, as confirmed by her three admissions to the ED during the study period (Figure 6). The first admission for suicidal ideation occurred just after her hospital discharge. She presented maximal suicidal ideation intensity that was ecologically assessed via emma, and she used the Call Module just before ED admission, and an Emotion Regulation Module just after. Two months later, in addition to the scheduled EMA, she filled in the questionnaires spontaneously several times with very high suicidal ideation scores. These spontaneous self-assessments were immediately followed by the use of the Call Module with a sharp decrease in suicidal ideation. Nevertheless, suicidal ideation rapidly increased again, leading to a new admission to the ED. About a month later, despite the lower suicidal ideation score at the spontaneous self-assessment and the use of the Emotion Regulation Module, she was admitted to the ED for an aborted suicide attempt by hanging.

During the study period, Patient 7 completed 66 EMA self-assessments. Specifically, she completed only $4.4 \%$ of the scheduled daily questionnaires due to technical problems (notifications not received), and about $75 \%$ of the weekly questionnaires, and she frequently filled in the questionnaires in a spontaneous way (39 times), particularly at specific times (without frequency decrease during the study period). She often used the Call Module (29 times), particularly to contact the SAMU (15 times), followed by the ED (7 times) and relatives ( 7 times). She also looked at Pictures (41 times) and listened to the Breathing Space Module (5 times).

A qualitative longitudinal analysis showed that the EMA made via the app allowed capturing suicidal ideation fluctuations that were not highlighted by the clinical follow-up visits (Figure 6). It also showed a regular use of the safety plan modules (at least one module per month) the frequency of which increased at specific times. For instance, in July the high intensity of suicidal ideation evaluated ecologically by emma corresponded to an increased use of the Call Module. December was 
characterized by many spontaneous EMA completions, lower suicidal intensity, and frequent use of the Emotion Regulation Module. This suggests that emma alarm thresholds triggered EMIs adapted to her condition severity.

\section{Patient 9}

Patient 9 is a 57 -year-old single woman living with her four children. She is unemployed with a disability living allowance for adults (Table 1). At inclusion, she had major depressive disorder, agoraphobia, post-traumatic disorder, and bipolar disorder II, according to the DSM-5. At the first clinical evaluation, suicidal ideation intensity was very high (C-SSRS score of 25/25) with suicide risk in the near future. She already committed eight suicide attempts, including one severe (Table 2). During the study, the clinician reported a decrease in suicidal thoughts at the 1-month follow-up visit, and then absence of suicidal thoughts at the 3-and 6-month visits.

Patient 9 filled in rarely the daily EMAs (10\%), but she completed $81.2 \%$ of the weekly EMAs, and filled in EMAs spontaneously 29 times. She completed $100 \%$ of the monthly questionnaires about her perception, experience and satisfaction about emma use. The longitudinal qualitative analysis (Figure 6) showed that from month 2 after inclusion, both the self-assessments made with emma and the hetero-assessments made during the visits did not detect any suicidal idea. Patient 9 used her safety plan only once at the very beginning of the study, when she still had suicidal thoughts.

\section{Patient 10}

Patient 10 is a 48-year-old woman, living with her husband and their two children. When included in the study she was on sick leave (Table 1). She had major depressive disorder and suicidal risk in the near future, according to the DSM-5, and very high suicidal ideation intensity (C-SSRS score of 24/25). She reported one suicide attempt and family history of suicide (Table 2). Patient 10's suicidal ideation decreased at the 1- and 3-month follow-up visits, but was higher again at the 6-month visit.

Patient 10 never filled in questionnaires spontaneously, only once the daily EMAs, and not often the weekly EMAs (35\%). She completed only one monthly questionnaire about her emma experience. She used her safety plan several times, mainly to call her relatives ( 3 times), the SAMU ( 3 times), and the ED (2 times). She also listened to the Breathing Space Module (3 times).

Patient 10 reported suicidal thoughts via emma only during a brief period (in October and early November) and at that occasion she used the Emotion Regulation Module, also only once (Figure 6). Self-assessment may have helped her to become aware of her condition and use the tools emma offers to regulate her emotions. This patient used the Call Module twice: immediately after her inclusion in the study, in August, when she had severe suicidal thoughts and suicide risk, and then at the end of November (no suicidal thought reported via emma at that time). Therefore, the app seems to be useful at times of crisis, even when patients do not complete the scheduled questionnaires. 
Figure 6. Case reports, Patients 7, 9, and 10.

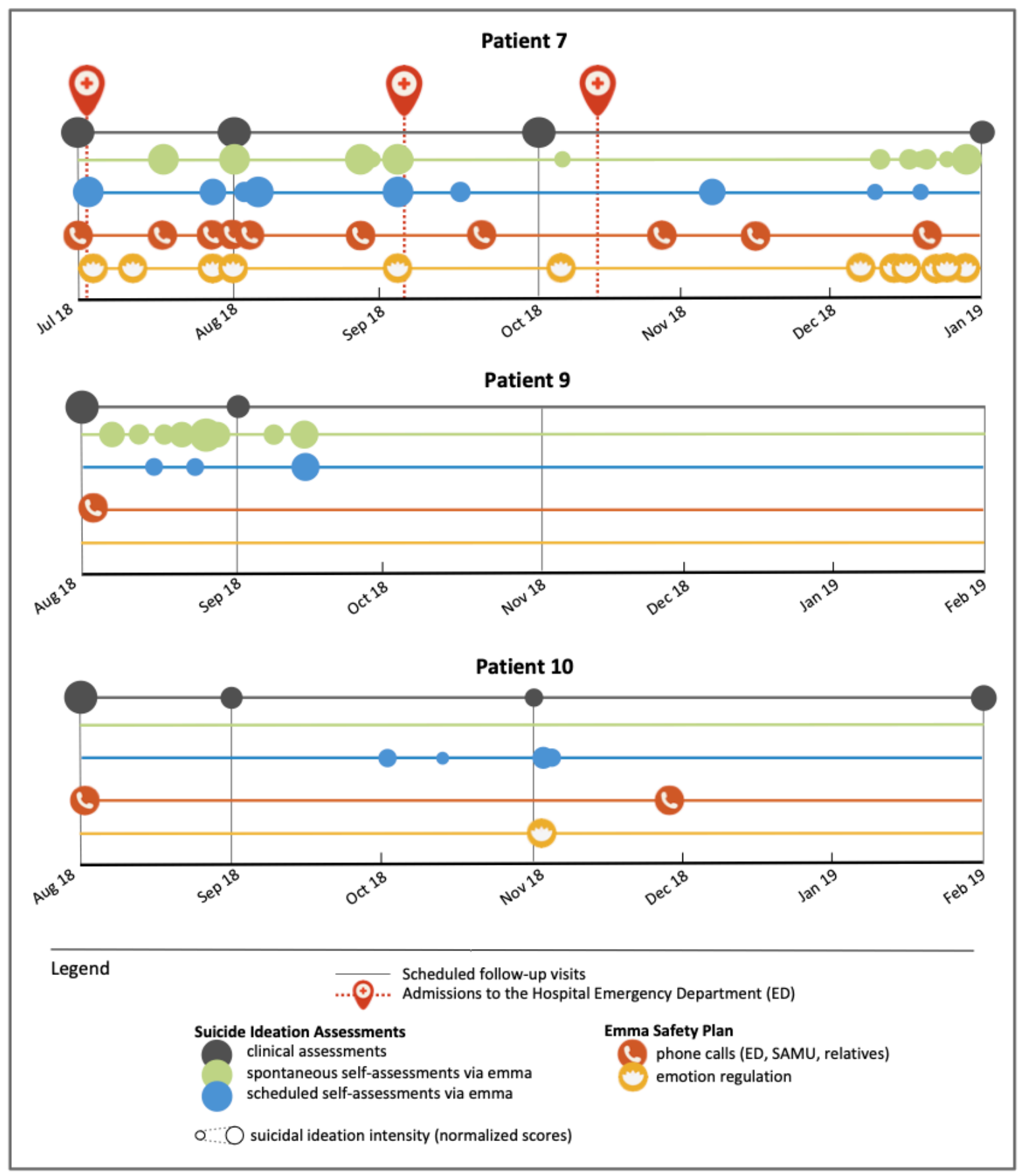

\section{Qualitative study}

The first qualitative feedbacks from the participants collected during the qualitative study (semidirective interviews) were very positive. They emphasized the support and the connectedness dimensions allowed by the app. During the co-design process, patients proposed to give the app a female name to personify it. The first users interviewed seemed to appreciate this, as stressed by a patient: "emma is like having a companion".

This "digital companion" seemed to help reducing the feeling of loneliness: "We have the feeling that we are not alone, that the software supports us". Moreover, this support comes at a critical time, after hospital discharge. To our knowledge, this period at very high suicide risk [19], when patients may experience painful loneliness in contrast to the time in hospital where they are followed by the healthcare team 24 hours per day, has not been much studied. "Thanks to emma, I did not feel alone 
when I left the hospital. I know emma less than my relatives, but I can tell her more". Emma also appeared to be a support, autonomy, and empowerment tool by helping people to use their own resources: "emma is an appointment with oneself. It is the memory of the patient: I know who to call." This empowerment was facilitated by the possibility to personalize the app: "It is important that we can each fill in the things that affect us and the things that impact us because we are all different and it allows targeting everyone specifically; it is good because it helps us deep down". These first qualitative interviews highlighted the interest of the co-design process that enabled patients to appropriate the digital tool.

\section{Discussion}

EMMA is an on-going study designed to develop a mHealth-based prediction algorithm for suicide prevention. The present report describes quantitatively and qualitatively the emma app use by the first 14 patients included in the study. Moreover, the in-depth analysis of its use by three patients brings more insights into the app use timeline, and how it might be integrated in the routine care. These descriptive results indicated that this type of digital tool could be accepted and used by patients at high risk of suicide. The study participation rate $(88 \%)$ was very good compared with other studies. For example, Hallensleben et al reported that $46.7 \%$ of inpatients with unipolar depression agreed to complete EMA [30]. As the EMMA Study plans to include 100 patients who will use the app for 6 months, a larger number of patients will perform EMA over a longer period of time compared with all previous studies [19].

Our analysis showed a heterogeneous use and engagement with the emma app, most often an under-use relative to our expectations. This could be interpreted as a poor adherence to the app $[77,78]$, and was partly caused by technical problems experienced by the first participants (e.g., notifications did not appear at the beginning of the study). Besides the simple quantitative measure of the app use, it was important also to evaluate the users' subjective experience [79]. As recommended [80], our evaluation was based on a mixed-method approach that combined: 1) automatically recorded metadata on emma use, 2) questionnaires on the app usefulness and satisfaction administered via the app and at the end of the protocol (MARS), and 3) a qualitative semi-structured interview on the participants' experiential and subjective experience at the end of the study. This should allow identifying different user profiles, and developing tailored prevention strategies [44].

The app was designed to strengthen the patients' connection to their natural support network (family, friends...) and also to the healthcare system, particularly through the Call Module promoting help-seeking at times of crisis. The connectedness philosophy implemented in emma is considered a strong protective factor for suicidal behaviors [82,83]. Emma does not replace the patients' relational supports, but increases them. This is important because it is thought that subjectively perceived and effectively received social supports [84] improve mental and physical well-being [85]. Emma has the potential to act on the quality of patients' social ties and their social pain that seems to be involved in suicidal crises [87]. During the first qualitative interviews, patients expressed the importance to feel supported by the software, to have the opportunity to "talk to emma" as a companion, to tell her things they would not dare to say to their relatives, to protect them and/or out of fear of the stigma that their confidences could generate.

For emma design, data from the scientific literature and the wishes and experiences of patient-users were integrated. The app specifically targets suicidal behavior and proposes an interactive and proactive content that is an effective prevention strategy [8,88-90]. Despite this scientific evidence, a recent literature review [60] identified very few suicide-specific apps (24) with safety planning (14) and that directly allow the user to seek support (13). Moreover, potentially harmful content that 
encourages self-harm and suicide [26] was identified, and many of the existing apps for suicide prevention have not been scientifically validated [48,60]. During the design phase, a patient indicated that he thought three apps were needed: "When we are doing well, not well, and not well at all". Therefore, emma was designed to be as adaptable as possible. The tailored adjustment of the technology-delivered program is also in line with evidence-based recommendations for mental health: "the app can recommend specific solutions to each user's specific problems" [46].

While the co-design methodology is recommended $[52,53]$ and constitutes a guarantee to develop a tool adapted to the users' needs, it requires a lot of rigor and benevolence. It seemed essential to us to consult patients very early and at all stages of this project through focus groups for the app design, then feedback from patients during prototype testing, and finally through qualitative interviews with emma user patients. However, as patients with suicidal behavior are a high-risk population, it is important to ensure that their participation in research respects the safety principle. Therefore, we put in place a trust-based exchange framework that was flexible enough to adapt to fluctuations in their condition. When carefully implemented, the participation of patients as partners can be a factor of empowerment and self-esteem restoration [91], as confirmed throughout this study.

In summary, emma is a unique opportunity, by integrating in the patient's life, to monitor with a fine granularity the emotional, psychological, social and physiological dimensions involved in suicidal ideas and behaviors and their contextualized interactions. Our preliminary results with an encouraging patient acceptance rate highlight the great inter- and intra-individual diversity of app usage patterns (EMA questionnaires completion rate and/or Safety Plan Modules use). Patients have different clinical and digital profiles and needs that require a highly scalable, interactive and customizable app.

Currently emma allows the active collection of the subjective state self-assessed by the user. However, we would like to complete it with a seamless [51,92] in situ collection of objective data, particularly on connectedness indicators that have been evaluated only in few studies related to suicide [19]. Therefore, we plan to implement digital phenotyping/footprinting $[15,93,94]$ in the app to collect all metadata on phone use (number, duration, direction of calls and sms) and activity on social media because they appear to be a very promising field of exploration and intervention in suicidology (Notredame in press).

\section{Conclusion}

Data on immediate and long-term risk of suicide are extremely sparse and based on measures with poor temporal resolution $[95,96]$. Emma is a great opportunity to capture the dynamics of suicidal ideas [44], and their translation into action in a contextualized way that allows a much more nuanced view of variables over time [18]. We hope that this digital tool will lead to scientific and clinical advances, and will allow identifying high-risk periods, and predicting the imminent risk, which is extremely challenging at the moment [27]. These fine-grained digital assessments and predictive mHealth-based interventions are promising tools for suicide prevention [57], because they represent an unprecedented opportunity to act at multiple levels through targeted, scalable and contextualized micro-interventions [98]. They might allow proposing just-in-time adaptive interventions (JITAI), defined by Nahum-Shani [99] as the right support (e.g., type, intensity) at the right time [26]. The challenge is now to integrate such digital interventions in the existing healthcare systems [54]. For instance, emma could be integrated in the ED procedures and become a complementary healthcare tool. In the patient's pocket, emma could provide individualized support when needed. The app could improve coordination among the different services (ED, crisis centers, hospital services, outpatient services, and general practitioners). However, the smooth and optimal integration of such digital tools in patient care requires the healthcare professionals' support. Indeed, they should not perceive these tools as disruptive elements in their daily clinical practice $[32,104]$, but as helps to improve the therapeutic relationship within a well-defined ethical social and legal framework. 


\section{References}

1. WHO. Preventing suicide: a global imperative. World Health Organization; 2014. ISBN:9241564776

2. WHO. Suicide. Fact sheet. 2016.

3. Hawton K. Suicide prevention: a complex global challenge. Lancet Psychiatry Elsevier Publishers; 2014;1(1):2-3.

4. Turecki G, Brent DA. Suicide and suicidal behaviour. Lancet Elsevier Ltd; 2015;ePub(ePub):ePub-ePub. [doi: 10.1016/S01406736(15)00234-2]

5. Hunt IM, Kapur N, Webb R, Robinson J, Burns J, Shaw J, Appleby L. Suicide in recently discharged psychiatric patients: a casecontrol study. Psychological medicine Cambridge University Press; 2009;39(3):443-449.

6. Lizardi D, Stanley B. Treatment engagement: a neglected aspect in the psychiatric care of suicidal patients. Psychiatric services (Washington, DC) 2010;61(12):1183-1191. PMID:21123401

7. Vuagnat A, Jollant F, Abbar M, Hawton K, Quantin C. Recurrence and mortality 1 year after hospital admission for non-fatal selfharm: a nationwide population-based study. Epidemiology and psychiatric sciences Cambridge University Press; 2019;1-10.

8. Christensen H, Batterham P, O'Dea B. E-Health Interventions for Suicide Prevention. International Journal of Environmental Research and Public Health 2014;11(8):8193-8212. [doi: 10.3390/ijerph110808193]

9. Campo J V. Youth suicide prevention: does access to care matter? Current opinion in pediatrics LWW; 2009;21(5):628-634.

10. Bruffaerts R, Demyttenaere K, Hwang I, Chiu W-T, Sampson N, Kessler RC, Alonso J, Borges G, de Girolamo G, de Graaf R. Treatment of suicidal people around the world. The British Journal of Psychiatry Cambridge University Press; 2011;199(1):64-70.

11. Mojtabai R, Olfson M, Sampson NA, Jin R, Druss B, Wang PS, Wells KB, Pincus HA, Kessler RC. Barriers to mental health treatment: results from the National Comorbidity Survey Replication. Psychological medicine Cambridge University Press; 2011;41(8):1751-1761.

12. Shand FL, Ridani R, Tighe J, Christensen H. The effectiveness of a suicide prevention app for indigenous Australian youths: study protocol for a randomized controlled trial. Trials BioMed Central; 2013;14(1):396.

13. Gulliver A, Griffiths KM, Christensen H. Perceived barriers and facilitators to mental health help-seeking in young people: a systematic review. BMC psychiatry BioMed Central; 2010;10(1):113.

14. Jaroszewski AC, Morris RR, Nock MK. Randomized controlled trial of an online machine learning-driven risk assessment and intervention platform for increasing the use of crisis services. Journal of consulting and clinical psychology American Psychological Association; 2019;87(4):370.

15. Kleiman EM, Turner BJ, Fedor S, Beale EE, Picard RW, Huffman JC, Nock MK. Digital phenotyping of suicidal thoughts. Depression and anxiety Wiley Online Library; 2018;35(7):601-608.

16. Hilty DM, Chan S, Hwang T, Wong A, Bauer AM. Advances in mobile mental health: opportunities and implications for the spectrum of e-mental health services. mHealth 2017;3(5):34-34. PMID:28894744

17. Selby EA, Yen S, Spirito A. Time varying prediction of thoughts of death and suicidal ideation in adolescents: weekly ratings over 6-month follow-up. Journal of Clinical Child \& Adolescent Psychology Taylor \& Francis; 2013;42(4):481-495.

18. Davidson CL, Anestis MD, Gutierrez PM. Ecological momentary assessment is a neglected methodology in suicidology. Archives of suicide research Taylor \& Francis; 2017;21(1):1-11.

19. Kleiman EM, Nock MK. Real-time assessment of suicidal thoughts and behaviors. Current opinion in psychology Elsevier; 2018;22:33-37.

20. Husky M, Olié E, Guillaume S, Genty C, Swendsen J, Courtet P. Feasibility and validity of ecological momentary assessment in the investigation of suicide risk. Psychiatry research Elsevier; 2014;220(1):564-570.

21. Gould MS, Marrocco FA, Kleinman M, Thomas JG, Mostkoff K, Cote J, Davies M. Evaluating iatrogenic risk of youth suicide screening programs: a randomized controlled trial. Jama American Medical Association; 2005;293(13):1635-1643.

22. Law MK, Furr RM, Arnold EM, Mneimne M, Jaquett C, Fleeson W. Does assessing suicidality frequently and repeatedly cause harm? A randomized control study. Psychological assessment American Psychological Association; 2015;27(4):1171.

23. Smith P, Poindexter E, Cukrowicz K. The effect of participating in suicide research: Does participating in a research protocol on suicide and psychiatric symptoms increase suicide ideation and attempts? Suicide and Life-Threatening Behavior Wiley Online Library; 2010;40(6):535-543.

24. Kleiman EM, Turner BJ, Fedor S, Beale EE, Huffman JC, Nock MK. Examination of real-time fluctuations in suicidal ideation and its risk factors: Results from two ecological momentary assessment studies. Journal of abnormal psychology American Psychological Association; 2017;126(6):726. 
25. Nock MK, Prinstein MJ, Sterba SK. Revealing the form and function of self-injurious thoughts and behaviors: A real-time ecological assessment study among adolescents and young adults. Journal of abnormal psychology American Psychological Association; 2009;118(4):816.

26. Torous J, Larsen ME, Depp C, Cosco TD, Barnett I, Nock MK, Firth J. Smartphones, sensors, and machine learning to advance real-time prediction and interventions for suicide prevention: a review of current progress and next steps. Current psychiatry reports Springer; 2018;20(7):51.

27. Bagge CL, Littlefield AK, Glenn CR. Trajectories of affective response as warning signs for suicide attempts: An examination of the 48 hours prior to a recent suicide attempt. Clinical psychological science Sage Publications Sage CA: Los Angeles, CA; 2017;5(2):259-271.

28. Bagge CL, Littlefield AK, Conner KR, Schumacher JA, Lee H-J. Near-term predictors of the intensity of suicidal ideation: An examination of the $24 \mathrm{~h}$ prior to a recent suicide attempt. Journal of Affective Disorders Elsevier; 2014;165:53-58.

29. Millner AJ, Lee MD, Nock MK. Describing and measuring the pathway to suicide attempts: A preliminary study. Suicide and LifeThreatening Behavior Wiley Online Library; 2017;47(3):353-369.

30. Hallensleben N, Glaesmer H, Forkmann T, Rath D, Strauss M, Kersting A, Spangenberg L. Predicting suicidal ideation by interpersonal variables, hopelessness and depression in real-time. An ecological momentary assessment study in psychiatric inpatients with depression. European psychiatry Elsevier; 2019;56:43-50.

31. Belsher BE, Smolenski DJ, Pruitt LD, Bush NE, Beech EH, Workman DE, Morgan RL, Evatt DP, Tucker J, Skopp NA. Prediction models for suicide attempts and deaths: a systematic review and simulation. JAMA psychiatry 2019;

32. Linthicum KP, Schafer KM, Ribeiro JD. Machine learning in suicide science: Applications and ethics. Behavioral sciences \& the law Wiley Online Library; 2019;

33. Franklin JC, Ribeiro JD, Fox KR, Bentley KH, Kleiman EM, Huang X, Musacchio KM, Jaroszewski AC, Chang BP, Nock MK. Risk factors for suicidal thoughts and behaviors: a meta-analysis of 50 years of research. Psychological Bulletin American Psychological Association; 2017;143(2):187.

34. Carter G, Milner A, McGill K, Pirkis J, Kapur N, Spittal MJ. Predicting suicidal behaviours using clinical instruments: systematic review and meta-analysis of positive predictive values for risk scales. The British Journal of Psychiatry Cambridge University Press; 2017;210(6):387-395.

35. Donker T, Blankers M, Hedman E, Ljotsson B, Petrie K, Christensen H. Economic evaluations of Internet interventions for mental health: A systematic review. Psychological Medicine 2015;45(16):3357-3376. PMID:26235445

36. Bernanke JA, Stanley BH, Oquendo MA. Toward fine-grained phenotyping of suicidal behavior: the role of suicidal subtypes. Molecular psychiatry Nature Publishing Group; 2017;22(8):1080.

37. Kessler RC, Stein MB, Petukhova M V, Bliese P, Bossarte RM, Bromet EJ, Fullerton CS, Gilman SE, Ivany C, LewandowskiRomps L. Predicting suicides after outpatient mental health visits in the Army Study to Assess Risk and Resilience in Servicemembers (Army STARRS). Molecular psychiatry Nature Publishing Group; 2017;22(4):544.

38. Kessler RC, Warner CH, Ivany C, Petukhova M V, Rose S, Bromet EJ, Brown M, Cai T, Colpe LJ, Cox KL. Predicting suicides after psychiatric hospitalization in US Army soldiers: the Army Study to Assess Risk and Resilience in Servicemembers (Army STARRS). JAMA psychiatry American Medical Association; 2015;72(1):49-57.

39. Walsh CG, Ribeiro JD, Franklin JC. Predicting risk of suicide attempts over time through machine learning. Clinical Psychological Science Sage Publications Sage CA: Los Angeles, CA; 2017;5(3):457-469.

40. Walsh CG, Ribeiro JD, Franklin JC. Predicting suicide attempts in adolescents with longitudinal clinical data and machine learning. Journal of child psychology and psychiatry Wiley Online Library; 2018;59(12):1261-1270.

41. Vahabzadeh A, Sahin N, Kalali A. Digital suicide prevention: can technology become a game-changer? Innovations in clinical neuroscience Matrix Medical Communications; 2016;13(5-6):16.

42. Stanley B, Brown GK. Safety planning intervention: a brief intervention to mitigate suicide risk. Cognitive and Behavioral Practice Elsevier; 2012;19(2):256-264.

43. Nuij C, van Ballegooijen W, Ruwaard J, De Beurs D, Mokkenstorm J, van Duijn E, de Winter RFP, O’Connor RC, Smit JH, Riper H. Smartphone-based safety planning and self-monitoring for suicidal patients: Rationale and study protocol of the CASPAR (Continuous Assessment for Suicide Prevention And Research) study. Internet interventions Elsevier; 2018;13:16-23.

44. Andreasson K, Krogh J, Bech P, Frandsen H, Buus N, Stanley B, Kerkhof A, Nordentoft M, Erlangsen A. MYPLAN-mobile phone application to manage crisis of persons at risk of suicide: study protocol for a randomized controlled trial. Trials BioMed Central; 2017;18(1):171. 
Brodsky BS, Spruch-Feiner A, Stanley B. The Zero Suicide Model: Applying evidence-based suicide prevention practices to clinical care. Frontiers in psychiatry Frontiers; 2018;9:33.

46. Bakker D, Kazantzis N, Rickwood D, Rickard N. Mental Health Smartphone Apps: Review and Evidence-Based Recommendations for Future Developments. JMIR Mental Health 2016;3(1):e7. PMID:26932350

47. Pauwels K, Aerts S, Muijzers E, De Jaegere E, van Heeringen K, Portzky G. BackUp: development and evaluation of a smartphone application for coping with suicidal crises. PLoS one Public Library of Science; 2017;12(6):e0178144.

48. de la Torre I, Castillo G, Arambarri J, López-Coronado M, Franco MA. Mobile Apps for Suicide Prevention: Review of Virtual Stores and Literature. JMIR mHealth and uHealth 2017;5(10):e130. PMID:29017992

49. Kreuze E, Jenkins C, Gregoski M, York J, Mueller M, Lamis DA, Ruggiero KJ. Technology-enhanced suicide prevention interventions: a systematic review. Journal of telemedicine and telecare SAGE Publications Sage UK: London, England; 2017;23(6):605-617.

50. Maheu MM, Nicolucci V, Pulier ML, Wall KM, Frye TJ, Hudlicka E. The interactive mobile app review toolkit (IMART): A clinical practice-oriented system. Journal of Technology in Behavioral Science Springer; 2017;1(1-4):3-15.

51. Bakker D, Kazantzis N, Rickwood D, Rickard N. Mental Health Smartphone Apps: Review and Evidence-Based Recommendations for Future Developments. JMIR Mental Health 2016;3(1):e7. PMID:26932350

52. Birnbaum F, Lewis DM, Rosen R, Ranney ML. Patient engagement and the design of digital health. Academic emergency medicine: official journal of the Society for Academic Emergency Medicine NIH Public Access; 2015;22(6):754.

53. Baker TB, Gustafson DH, Shah D. How can research keep up with eHealth? Ten strategies for increasing the timeliness and usefulness of eHealth research. Journal of medical Internet research JMIR Publications Inc.; 2014;16(2).

54. Biagianti B, Hidalgo-Mazzei D, Meyer N. Developing digital interventions for people living with serious mental illness: perspectives from three mHealth studies. Evidence-based mental health Royal College of Psychiatrists; 2017;ebmental-2017.

55. Hawton K, Witt KG, Salisbury TLT, Arensman E, Gunnell D, Townsend E, van Heeringen K, Hazell P. Interventions for self-harm in children and adolescents. Cochrane database of systematic reviews John Wiley \& Sons, Ltd; 2015;(12).

56. Stallard P, Porter J, Grist R. A smartphone app (BlueIce) for young people who self-harm: open phase 1 pre-post trial. JMIR mHealth and uHealth JMIR Publications Inc.; 2018;6(1).

57. Franco-Martín MA, Muñoz-Sánchez JL, Sainz-de-Abajo B, Castillo-Sánchez G, Hamrioui S, De La Torre-Díez I. A systematic literature review of technologies for suicidal behavior prevention. Journal of medical systems Springer; 2018;42(4):71.

58. Krueger RA, Casey MA. Focus groups: A practical guide for applied research. Sage publications; 2014. ISBN:1483365220

59. Heron KE, Smyth JM. Ecological momentary interventions: incorporating mobile technology into psychosocial and health behaviour treatments. British journal of health psychology 2010 Feb;15(Pt 1):1-39. PMID:19646331

60. Larsen ME, Nicholas J, Christensen H. A systematic assessment of smartphone tools for suicide prevention. PloS one Public Library of Science; 2016;11(4):e0152285.

61. Sheehan D V, Lecrubier Y, Sheehan KH, Amorim P, Janavs J, Weiller E, Hergueta T, Baker R, Dunbar GC. The MiniInternational Neuropsychiatric Interview (MINI): the development and validation of a structured diagnostic psychiatric interview for DSM-IV and ICD-10. Journal of clinical psychiatry Physicians Postgraduate Press; 1998;

62. Rush AJ, Trivedi MH, Ibrahim HM, Carmody TJ, Arnow B, Klein DN, Markowitz JC, Ninan PT, Kornstein S, Manber R. The 16Item Quick Inventory of Depressive Symptomatology (QIDS), clinician rating (QIDS-C), and self-report (QIDS-SR): a psychometric evaluation in patients with chronic major depression. Biological psychiatry Elsevier; 2003;54(5):573-583.

63. Posner K, Brown GK, Stanley B, Brent DA, Yershova K V, Oquendo MA, Currier GW, Melvin GA, Greenhill L, Shen S. The Columbia-Suicide Severity Rating Scale: initial validity and internal consistency findings from three multisite studies with adolescents and adults. American Journal of Psychiatry Am Psychiatric Assoc; 2011;168(12):1266-1277.

64. Weisman AD, Worden JW. Risk-rescue rating in suicide assessment. Archives of General Psychiatry American Medical Association; 1972;26(6):553-560.

65. Beck AT, Kovacs M, Weissman A. Assessment of suicidal intention: the Scale for Suicide Ideation. Journal of consulting and clinical psychology American Psychological Association; 1979;47(2):343.

66. Bernstein DP, Stein JA, Newcomb MD, Walker E, Pogge D, Ahluvalia T, Stokes J, Handelsman L, Medrano M, Desmond D. Development and validation of a brief screening version of the Childhood Trauma Questionnaire. Child abuse \& neglect Elsevier; 2003;27(2):169-190.

67. Russell D, Peplau LA, Cutrona CE. The revised UCLA Loneliness Scale: concurrent and discriminant validity evidence. Journal of personality and social psychology American Psychological Association; 1980;39(3):472. 
68. Steptoe A, Shankar A, Demakakos P, Wardle J. Social isolation, loneliness, and all-cause mortality in older men and women. Proceedings of the National Academy of Sciences National Acad Sciences; 2013;110(15):5797-5801.

69. Guédeney N, Fermanian J, Bifulco A. La version française du Relationship Scales Questionnaire de Bartholomew (RSQ, Questionnaire des échelles de relation): étude de validation du construit. L'encéphale Elsevier; 2010;36(1):69-76.

70. Beck AT, Weissman A, Lester D, Trexler L. The measurement of pessimism: the hopelessness scale. Journal of consulting and clinical psychology American Psychological Association; 1974;42(6):861.

71. Whiteside SP, Lynam DR, Miller JD, Reynolds SK. Validation of the UPPS impulsive behaviour scale: a four-factor model of impulsivity. European Journal of Personality: Published for the European Association of Personality Psychology Wiley Online Library; 2005;19(7):559-574.

72. Dan-Glauser ES, Scherer KR. The Difficulties in Emotion Regulation Scale (DERS). Swiss Journal of Psychology Verlag Hans Huber; 2012;

73. Van Orden K-A, Cukrowicz KC, Witte TK, Joiner Jr TE. Thwarted belongingness and perceived burdensomeness: construct validity and psychometric properties of the Interpersonal Needs Questionnaire. Psychological assessment American Psychological Association; 2012;24(1):197.

74. Linehan MM, Goodstein JL, Nielsen SL, Chiles JA. Reasons for staying alive when you are thinking of killing yourself: the Reasons for Living Inventory. Journal of consulting and clinical psychology American Psychological Association; 1983;51(2):276.

75. Morgan J, Farsides T. Measuring meaning in life. Journal of happiness Studies Springer; 2009;10(2):197-214.

76. Wade J, Sherbourne C. The MOS 36-item short-form health survey (SF-36). Medical Care 1992;Care 30:47.

77. Donkin L, Christensen H, Naismith SL, Neal B, Hickie IB, Glozier N. A systematic review of the impact of adherence on the effectiveness of e-therapies. Journal of medical Internet research JMIR Publications Inc.; 2011;13(3).

78. Kelders SM, Kok RN, Ossebaard HC, Van Gemert-Pijnen JEWC. Persuasive system design does matter: a systematic review of adherence to web-based interventions. Journal of medical Internet research JMIR Publications Inc.; 2012;14(6).

79. Smith W, Ploderer B, Wadley G, Webber S, Borland R. Trajectories of engagement and disengagement with a story-based smoking cessation app. Proceedings of the 2017 CHI Conference on Human Factors in Computing Systems ACM; 2017. p. $3045-3056$.

80. Sieverink F, Kelders SM, van Gemert-Pijnen JEWC. Clarifying the concept of adherence to eHealth technology: systematic review on when usage becomes adherence. Journal of medical Internet research JMIR Publications Inc.; 2017;19(12).

81. Stoyanov SR, Hides L, Kavanagh DJ, Zelenko O, Tjondronegoro D, Mani M. Mobile app rating scale: a new tool for assessing the quality of health mobile apps. JMIR mHealth and uHealth JMIR Publications Inc.; 2015;3(1).

82. Santini ZI. The impact of social networks and social support on mental disorders and mortality. Universitat de Barcelona; 2016;

83. Whitlock J, Wyman PA, Moore SR. Connectedness and suicide prevention in adolescents: pathways and implications. Suicide and life-threatening behavior Wiley Online Library; 2014;44(3):246-272.

84. Nurullah AS. Received and provided social support: A review of current evidence and future directions. American Journal of Health Studies 2012;27(3):173-188.

85. McDougall MA, Walsh M, Wattier K, Knigge R, Miller L, Stevermer M, Fogas BS. The effect of social networking sites on the relationship between perceived social support and depression. Psychiatry research Elsevier; 2016;246:223-229.

86. Gottlieb BH. Selecting and planning support interventions. Social support measurement and intervention: A guide for health and social scientists 2000;195-220.

87. Conejero I, Olié E, Calati R, Ducasse D, Courtet P. Psychological pain, depression, and suicide: recent evidences and future directions. Current psychiatry reports Springer; 2018;20(5):33.

88. Inagaki M, Kawashima Y, Kawanishi C, Yonemoto N, Sugimoto T, Furuno T, Ikeshita K, Eto N, Tachikawa H, Shiraishi Y. Interventions to prevent repeat suicidal behavior in patients admitted to an emergency department for a suicide attempt: a metaanalysis. Journal of affective disorders Elsevier; 2015;175:66-78.

89. Hogan MF. Better suicide screening and prevention are possible. JAMA psychiatry American Medical Association; 2016;73(11):1111-1112.

90. Linehan MM, Comtois KA, Murray AM, Brown MZ, Gallop RJ, Heard HL, Korslund KE, Tutek DA, Reynolds SK, Lindenboim N. Two-year randomized controlled trial and follow-up of dialectical behavior therapy vs therapy by experts for suicidal behaviors and borderline personality disorder. Archives of general psychiatry American Medical Association; 2006;63(7):757-766.

91. Morgiève M, Ung Cand Y, pédagogique à R. Diminuer l'impact des troubles obsessionnels compulsifs par des modifications de l'environnement physique Une étude de preuve de concept. 
92. Berrouiguet S, Ramírez D, Barrigón ML, Moreno-Muñoz P, Camacho RC, Baca-García E, Artés-Rodríguez A. Combining Continuous Smartphone Native Sensors Data Capture and Unsupervised Data Mining Techniques for Behavioral Changes Detection: A Case Series of the Evidence-Based Behavior (eB2) Study. JMIR mHealth and uHealth JMIR Publications Inc., Toronto, Canada; 2018;6(12):e197.

93. Onnela J-P, Rauch SL. Harnessing smartphone-based digital phenotyping to enhance behavioral and mental health. Neuropsychopharmacology Nature Publishing Group; 2016;41(7):1691.

94. Insel TR. Digital Phenotyping: Technology for a New Science of Behavior. JAMA 2017;

95. Coppersmith G, Ngo K, Leary R, Wood A. Exploratory analysis of social media prior to a suicide attempt. Proceedings of the Third Workshop on Computational Lingusitics and Clinical Psychology 2016. p. 106-117.

96. Spangenberg L, Forkmann T, Glaesmer H. Investigating dynamics and predictors of suicidal behaviors using ambulatory assessment. neuropsychiatrie Springer; 2015;29(3):139-143.

97. Marzano L, Bardill A, Fields B, Herd K, Veale D, Grey N, Moran P. The application of 'mHealth'to mental health: opportunities and challenges. The Lancet Psychiatry 2015;

98. Briffault X, Morgiève M, Courtet P. From e-Health to i-Health: Prospective Reflexions on the Use of Intelligent Systems in Mental Health Care. Brain Sciences 2018;(8(98):1-16).

99. Nahum-Shani I, Smith SN, Spring BJ, Collins LM, Witkiewitz K, Tewari A, Murphy SA. Just-in-time adaptive interventions (JITAIs) in mobile health: key components and design principles for ongoing health behavior support. Annals of Behavioral Medicine Oxford University Press US; 2017;52(6):446-462.

100. Costanza A, Ambrosetti J, Wyss K, Bondolfi G, Sarasin F, Khan RA. Prévenir le suicide aux urgences: de la «Théorie Interpersonnelle du Suicide» à la connectedness. Revue médicale suisse 2018;14(593):335-338.

101. Berrouiguet S, Larsen ME, Mesmeur C, Gravey M, Billot R, Walter M, Network H, Lemey C, Lenca P. Toward mHealth brief contact interventions in suicide prevention: case series from the suicide intervention assisted by messages (SIAM) randomized controlled trial. JMIR mHealth and uHealth JMIR Publications Inc., Toronto, Canada; 2018;6(1):e8.

102. Meehan J, Kapur N, Hunt IM, Turnbull P, Robinson J, Bickley H, Parsons R, Flynn S, Burns J, Amos T. Suicide in mental health in-patients and within 3 months of discharge: national clinical survey. The British Journal of Psychiatry Cambridge University Press; 2006;188(2):129-134.

103. Berrouiguet S, Alavi Z, Vaiva G, Courtet P, Baca-García E, Vidailhet P, Gravey M, Guillodo E, Brandt S, Walter M. SIAM (Suicide intervention assisted by messages): the development of a post-acute crisis text messaging outreach for suicide prevention. BMC Psychiatry 2014;14:294. PMID:25404215

104. Kilsdonk E, Peute LW, Jaspers MWM. Factors influencing implementation success of guideline-based clinical decision support systems: A systematic review and gaps analysis. International journal of medical informatics Elsevier; 2017;98:56-64. 


\section{Acknowledgments}

First, we would like to thank Christine, Patrice, Romane, Jonathan, Astate, and Claire, the co-designer patients who improved emma! We would like to thank Dr. Déborah Ducasse for her contribution that greatly enriched the app content and Kathlyne Dupuis-Maurin for her unfailing involvement in this research. Thanks to the NERB team: Luc Mallet, Sirenia Lizbeth Mondragón-González and Karim N'Diaye for his creative help.

This study would not have been possible without the support of the FondaMental Chair for the prevention of suicidal behavior created by the FondaMental Foundation, led by Professor Philippe Courtet and supported by SNCF, SNCF réseau, and SNCF mobilité.

This innovative project received the Marcel Dassault Research Award for Research on Mental IIInesses in 2014. Finally, we would like to thank the Clinea and OC Santé Clinics for their support. 
Supplemental Table. Adverse events during the follow-up

\begin{tabular}{|c|c|c|c|c|}
\hline Patient & Number of suicide attempts & $\begin{array}{l}\text { Aborted suicide } \\
\text { attempts }\end{array}$ & $\begin{array}{l}\text { Number of emergency } \\
\text { department visits }\end{array}$ & Premature study stop \\
\hline 1 & & & 1 (road accident) & \\
\hline 2 & $\begin{array}{l}1 \text { (voluntary drug ingestion) } \\
1 \text { (bladed weapon) }\end{array}$ & & 2 (suicide attempts) & $\begin{array}{l}\text { Exclusion (deprived of } \\
\text { liberty) before visit } 1\end{array}$ \\
\hline 3 & & & 3 (suicidal ideation) & \\
\hline \multicolumn{5}{|l|}{4} \\
\hline \multicolumn{5}{|l|}{5} \\
\hline \multicolumn{5}{|l|}{6} \\
\hline 7 & & 1 (hanging) & 3 (suicidal ideation) & \\
\hline \multicolumn{5}{|l|}{8} \\
\hline \multicolumn{5}{|l|}{9} \\
\hline \multicolumn{5}{|l|}{10} \\
\hline \multicolumn{5}{|l|}{11} \\
\hline 12 & 1 (voluntary drug ingestion) & & & \\
\hline \multicolumn{5}{|l|}{13} \\
\hline 14 & & & & Withdrawal before visit 1 \\
\hline
\end{tabular}

